\title{
BEGINSELEN VAN KERKELIJKE RECHTSPRAAK
}

De laatste jaren is er meer belangstelling ontstaan voor de inhoud en werking van het gereformeerde kerkrecht. Enerzijds wordt gewezen op de veranderlijkheid van de Kerkorde en wordt verandering met het oog op aardrijkskundige en tijdsomstandigheden aanbevolen. ${ }^{1}$ Anderzijds wordt gewaarschuwd tegen reglementering rondom de Kerkorde, tegen onkritisch gebruik van handleidingen ${ }^{2}$ en tegen tendentieuze persoonlijke standpunten ${ }^{3}$ zonder voldoende acht te slaan op de tekst van de Kerkorde zelf. Het gevaar is groot dat in de kerkelijke rechtspraak te biecht wordt gegaan bij wereldlijk recht, dat in zichzelf niet voldoet aan de Bijbelse geboden. We beschouwen kerkelijke geschillen dan misschien als „koue regsake" in plaats van als gewetenscrises, waarin broeders van hetzelfde huis verkeren.

Het is nodig om de Schriftuurlijke beginselen voor de kerkelijke rechtspraak te herontdekken. Deze behoren zelfs voor de wereldlijke rechtspraak, die zich veelal verliest in formalisme en strictum jus in plaats van de Bijbelse gerechtigheid en billijkheid na te streven, tot voorbeeld te zijn. Niet omgekeerd. Intussen is het kwalijk als kerkelijke rechtspraak zelfs de toets van wereldlijk recht niet zou verdragen.

Een begin met deze herontdekking is in de vijftiger jaren gedaan door prof. P. Deddens uit Kampen, die de resultaten daarvan publiceerde in De Reformatie. Ik geef daarvan de volgende beknopte weergave.

Wat heeft naar het Woord in de kerk van Christus als recht te gelden? We zijn niet klaar met bezit en hantering van de in de Kerkorde opgenomen artikelen zonder meer. We lopen dan gevaar, die kerkorde te zien als een zelfstandige grootheid, los van het Woord, een codex van utiliteitsbepalingen, waarbij de man met de grootste scherpzinnigheid, de meeste Ausdauer, de langste adem en de sterkste overredingskracht het pleit wint. We hebben behoefte aan „Ontdekking der ogen” (Psalm 119 : 18), aan wijsheid, aan liefde, aan kloekheid, aan discretie, aan voorzichtigheid. Een onmisbaar vereiste is kennis van het Woord des Heren. De Schrift moet het eerste en het laatste Woord hebben: heel de Kerkenorde, alle overeengekomen bepalingen dienen bezien en toegepast in het licht van het Woord. ${ }^{4}$

\section{Richters en ambtlieden in Deuteronomium}

In Deuteronomium $16: 18-20$ worden richters en ambtlieden verordend. De richter (of rechter) heeft te waken zowel voor de handhaving van de eerste als de tweede tafel van de wet, schuldigen te straffen en verdrukten te verlossen zowel in normale als abnormale tijden en in binnenland en buitenland. De weldaad van Jahweh was dat Hij het ambt van rechter verordende om daardoor afdwaling te voorkomen of de kop in te drukken zodra ze zich vertoonde. De ambtlieden waren vermoedelijk als ondergeschikte ambtenaren bij 
de procesvoering en de executic ingeschakeld, waarbij de rechters de leiding hadden. ${ }^{5}$

De rechtspraak is locaal geregeld nadat het volk zich in Kanaän gevestigd heeft. Dit leert vergelijking van Deut. 16 : 18 met Deut. $1: 15$. De rechtspraak wordt van de hoofden naar de steden verlegd. Dit is van betekenis voor de ontwikkeling en principiële fundering van ons kerkrecht: enerzijds hierin, dat de zelfstandigheid van de plaatselijke kerk een wezenlijk element is voor de opbouw van de gemeente; een groeiend kerkelijk leven eist geen sterke centralisatie, doch juist decentralisatie; anderzijds dat de Schrift leert dat aan historisch gegroeide instellingen nimmer star vastgehouden moet worden, doch juist vordert een soepele aanpassing aan veranderde omstandigheden. De koning had een heel speciale taak. Hij greep niet in in de bevoegdheden der locale rechters, doch had te waken dat de ene stam het recht van de andere stam niet aantastte. ${ }^{6}$

In Deut. $17: 6$ gaat het om getuigen bij de rechtspraak. Daarvan kan dood of leven afhangen. „Op de mond" van getuigen is op hun verklaring. Om valse verklaringen te voorkomen moeten er twee of drie getuigen zijn. Zie ook 2 Cor. $13: 1$. Men weet hoe talrijk in de bijbel de klachten zijn over vals getuigenis: Ps. 27 : $12 ; 35: 11$; Spr. $6: 19 ; 12: 17 ; 19: 28$ etc. De Here heeft deze zonde tegengegaan in het negende gebod, en ook maatregelen getroffen om zijn volk tegen zulke bozen te beveiligen. Door de getuigen te verplichten de eerste te zijn bij de executie dwingt Jahweh hen om zelf de verantwoordelijkheid van wat ze doen, zich scherp voor ogen te stellen. In Deut. $17: 2$ e.v. is de afgodendienst slechts voorbeeld van een misdaad, die gerechtelijk wordt vervolgd. De nadruk ligt hier op het nauwkeurig verhoor, het grondige onderzoek, de terechtstelling, het getuigenis der getuigen, en hun aandeel aan de terechtstelling - kortom op de gerechtelijke procedure als zodanig. Daarin sluit zich de wet nauw aan bij hoofdstuk $16: 18$. Beide wetten dienen om ons te doen zien hoe nieuw voor deze rechters hun taak was. $\mathrm{Zij}$ behoeven en ontvangen aanwijzingen, omdat ze nog ongeoefend zijn.?

Als de rechters niet bij machte blijken om een zaak te ontwarren, is dat niet maar ongelukkig voor hen, doch betekent dat een misère voor geheel Israel, omdat het nu met onoplosbare moeilijkheden blijft zitten. De hele rechtspleging is ondergeschikt aan het leven van het volk naar de geboden; vgl. ook Deut. $16: 20$. Het volk moet deze zaak dan aan de priesters en de rechters gezamenlijk voorleggen (Deut. $17: 8,9$ ) bij het heiligdom ter plaatse of het regionale heiligdom. De rechters die alleen de zaak niet konden ontwarren worden met de priesters aangevuld tot een college ad hoc. We kunnen wel onmiddellijk begrijpen waarom de priesters er bij geroepen worden. De rechters waren leken, $16: 18$, die wel moesten beantwoorden aan de eisen van wijsheid en onkreukbaarheid, vgl. $16: 19$, maar ze waren toch vooral mensen van de praktijk. De bestudering der wet was veelmeer het werk der priesters. De verhouding tussen beide groepen was ongeveer die tussen predikant en hoogleraar; de één zit in de praktijk van het werk, de ander is een man van studie vooral. Als nu de eerste, ondanks alle praktische ervaring, geen 
analoog geval kan noemen, waarnaar hij een actuele kwestie kan beoordelen, kan de tweede vanwege zijn bredere Schriftstudie hem te hulp komen, en hem dingen onder de aandacht brengen, waarop de eerste niet gelet heeft en zo behulpzaam zijn om de zaak onder zijn bereik en in zijn machi te krijgen. De priesters en de rechters hebben dan samen de taak om na onderzoek de zaak van het recht in een gezaghebbende uitspraak te beslissen. ${ }^{9}$

\section{Gedachten uit het exegetisch werk van prof. B. Holwerda}

1) De Here zorgt in Zijn kerk voor de handhaving van het recht. Hij stelt het ambt in en roept daartoe; in abnormale tijden verwekt Hij charismatici, de „richters"; groter weldaad is het, dat Hij het gewone ambt van rechter verordent, en daardoor afdwaling zoekt te voorkomen, of wel de kop wil zien ingedrukt, zodra ze zich vertoont.

2) De bedoeling van het rechter-ambt is om het leven van Gods volk te zegenen en rijk te maken; de Here legt daarin Zijn volk niet onder een juk van dienstbaarheid, want de ambtsdragers zijn er niet in de kerk om te heersen, maar om te dienen.

3) Bij de instelling van het rechtersambt ontbreken technische bijzonderheden, over de organisatie van de rechtspraak horen we weinig. De bedoeling is blijkbaar, dat als maar voor de handhaving van het recht gezorgd wordt, er een grote mate van vrijheid kan worden gelaten inzake de wijze, waarop men de zaak aanpakt.

4) Het ambt van rechters is voor Israël een levenskwestie; toch is er in de concrete uitwerking van dit principe een aanmerkelijk verschil: eerst Mozes alleen, daarna de „zware” zaken voor Mozes, de „lichte" voor de „oversten": Exodus 18 : 25, 26.

In Kanaän decentralisatie: daar is iets te zien van de ,zelfstandigheid der plaatselijke kerk"; daar wordt de rechtspraak naar de steden verlegd, zonder dat deze nu independentistisch naast elkaar komen te staan. Voorts heeft de stam toe te zien, dat elke stad deze ambtsdragers aanwijst. ${ }^{10}$

5) Wie recht heeft te spreken, moet uitbrengen een gericht der gerechtigheid, een vonnis in vrijsprekende of veroordelende zin. Het woord ,gerechtigheid" spreekt niet van een abstracte ideële norm, maar heeft op het oog: wat beantwoordt aan de eisen van een gemeenschap met een vast verbondsstatuut. Geen formalistische interpretatie van, ,gerechtigheid"! Geen spanning tussen recht en liefde; die twee vallen samen; ,gerechtigheid" heeft heel vaak de betekenis van „barmhartigheid".

6) Het volk, dat geroepen is rechters aan te stellen, is ook verantwoordelijk voor rechtsverkrachting; het moet stipt gehoorzaam zijn aan de rechterlijke uitspraken, waarmede echter allerminst een slaafs en blindelings sanctioneren bedoeld is, en een critische beoordeling niet uitsluit, maar vergt; daarom ook moet het volk zich tegen de uitvoering van onrechtvaardige vonnissen verzetten.

7) Verboden wordt alle corruptie bij de rechtspraak: geen buigen van het gericht (dat is: de persoon in rekening brengen, zich 
door zijn positie of door de onderlinge relatie laten verleiden, geen recht te doen); ook geen aanneming van het geschenk (geschenken vertroebelen de blik en verblinden, zodat men niet meer onbevangen en onbevooroordeeld in zijn uitspraak is).

8) De zin van het rechtersambt is de exclusieve, totale gerechtigheid. De rechterlijke ambtsdienst is er niet terwille van de rechters en van rechterlijke hoogheid, maar deze ambtsdienst bedoelt het volk te brengen tot en te bewaren bij een leven van louter gerechtigheid.

9) Van de kant der rechters begint de rechtshandeling met het instellen van een nauwkeurig en grondig onderzoek. Elke slordigheid en onnauwkeurigheid kan hier die meest ernstige gevolgen hebben. De basis voor verdere rechtshandelingen mag niet wankel zijn, maar moet stevig wezen; de rechters moeten niet afgaan op geruchten, maar op feiten; men mag niet rusten, eer de zaak is komen vast te staan.

10) Dit wordt paraenetisch toegelicht aan de hand van het eerste gebod (afgoderij); wie zich daaraan schuldig maakt heeft het fundament van Israël verbroken, heeft zich geplaatst buiten de gemeenschap, want hij heeft de binding aan de HERE prijsgegeven. Naar het gevoelen van prof. Holwerda ligt hier de wortel voor de artikelen 79 en 80 van de Kerkenorde: grove zonden, die zelfs voor de wereld veelal eerloos maken, en daarom in elk gewoon lid reeds de afsnijding waardig zijn. ${ }^{11}$

11) Een vonnis kan alleen worden geveld op grond van voldoend getuigenis; onder Israël worden minstens twee "getuigen" wier getuigenis gelijkluidend moest zijn, gevorderd: de eerste getuige is de aanklager, omdat hij een beschuldiging inbrengt, die volhoudt en bekrachtigt; de tweede en eventueel derde getuige zijn de personen, die hetzelfde gezien hebben als de aanklager, en dus herhalen wat hij zei.

12) De getuigen moeten in de eerste plaats de verantwoordelijkheid voor het vonnis dragen: zij zijn de eersten bij de executie. Maar heel Israël moet de executie mede uitvoeren: heel het volk moet meedoen om de haard van infectie op te ruimen. Het volk gaat, evenals de rechter, af op het getuigenis der ,getuigen": wat een verantwoordelijkheid voor deze laatsten, een waar en zuiver getuigen is af te leggen!

13) In zeer ingewikkelde gevallen, als de rechters er niet uit kunnen komen, moet het volk gaan tot de priesters en rechters samen (geen vast gemengd college, doch een vergadering ad hoc). De rechters krijgen dus in tweede instantie met dezelfde zaak te maken; de priester kan de rechter, uit hoofde van zijn meerdere Schriftkennis, dingen onder de aandacht brengen, waarop de eerste niet gelet heeft.

14) De uitspraak van deze vergadering is geen advies, maar gezaghebbend en bindend: de Here vervult Zijn belofte van Ex. 20 : 24 e.v. alzo, dat Hij de zegen van de oplossing van onoplosbare vragen brengt door de mond van Zijn dienaren; de Here stelt aldus het recht in de gemeenschap van Israël veilig: de wet is een zeer 
evangelische genade.

15) De uitspraak van priesters en rechters moet stipt gehoorzaamd worden: wie haar verwerpt verwerpt de Here, wordt wezenlijk een Kanaäniet, en verdient met de dood gestraft te worden.

16) Als deze boosheid niet met de dood gestraft zou worden, zou dit kwaad van verwerping van de Here om zich heen grijpen, heel Israël in weerspannigheid de Here opzij zetten, en de gave van het land verspelen. De tucht over de enkeling beoogt het behoud van de gemeente (Zondag 31 Catechismus).

17) In tijden van verval, als de kennis der wet bijna is teloor gegaan, belasten koningen wel Levieten met de rechtspraak, mensen met de wet vertrouwd, om de rechtspleging weer op gang te helpen. ${ }^{12}$

\section{Kerkorde en staatswet}

De Kerkorde moet niet als een staatswet gehanteerd worden, omdat wereldlijk en kerkelijk recht onderscheiden zijn.

Het eerste dwingt nakoming door straffen en andere sancties af; het andere wil vrije gehoorzaamheid uit liefde; het eerste straft misdadigers ook al bekeren zij zich; kerkelijke censuur eindigt bij berouw en boetvaardigheid van de zondaar; het eerste let op uitwendige gedragingen van mensen; het andere ook op de innerlijke gezindheid; het eerste kent de regel ne bis in idem; het andere niet; het eerste mag niet toezien of wetten tegen de grondwet ingaan; de kerk moet verwerpen alles wat strijdt met de Wet Gods, desnoods tegen alle kerkelijke ordening en beslissings in.

\section{Het karakter van de Kerkenorde}

1. vormgeving aan enkele Schriftuurlijke beginselen en regelingen ter voorkoming van willekeur en onordelijkheid;

2. dat zij de consciëntie nooit rechtstreeks kan binden. De K.O. is immers evenals de Belijdenis appellabel en examinabel aan het Woord Gods;

3. dat zij niet onveranderlijk is. In het belang der kerken is zij voor wijziging vatbaar (art. 86 K.O.);

4. dat zij kort moet zijn en kerkelijke juristerij moet voorkomen, terwijl zij grote ruimte moet laten voor het oordeel van ambtsdragers;

5. dat zij zo duidelijk mogelijk moet zijn, zodat ook het gewone kerklid in staat is haar te verstaan en toe te passen;

6. dat de formele binding aan haar letter haar niet mag laten ontaarden in een last van menselijke bepalingen, - waaraan letterlijk gebonden wordt. ${ }^{13}$

\section{Bijbel en Kerkorde}

In een kerkelijk geschil moet eerst de Bijbel open - dan de Kerkorde. Dit betekent dat indien een kerkeraad onrecht heeft gepleegd, de verontrechte die raad eerst moet terechtwijzen en bestraffen volgens Leviticus $19: 17$ en Matth. $18: 15$ en pas wanneer 
dit geen resultaat heeft zich kan beroepen op de classis volgens art. 31 K.O. ${ }^{14}$

\section{Recht om gehoord te worden}

Bij het onderzoek van een zaak moeten betrokkenen de gelegenheid krijgen om gehoord te worden: Exodus $18: 13-16$. Salomo had een aparte rechtzaal gemaakt in het koninklijk paleis (1 Kon. $7: 7)$ en daar verschenen partijen om mondeling het pleit te voeren. Vgl. ook Deut. 1 : 16; $21: 20 ; 25: 1$; Spreuken 18:17; 1 Kon. 3; 16 v. Christus wordt ook gehoord door Annas, Kajafas, Herodus, Pilatus. Paulus wordt gehoord door Felix, Festus en Agrippa en hij gaat in appèl om door de Keizer gehoord te worden.

\section{Degelijk onderzoek}

De rechters worden vermaand ter dege onderzoek te doen en grondig na te vragen; Deut. $13: 14 ; 17: 4 ; 19: 18$. Want het zoeken van het recht heet: tot God komen, voor God verschijnen: Ex. $21: 6$; 22 : 8; Deut. 19 : 17, want het gericht is Godes: Deut. 1 : 17, en de rechters, omdat ze optreden in de Naam des Heren, zijn door God als Zijn gevolmachtigden geroepen om recht te doen en heten goden: Psalm 82. ${ }^{10}$

\section{De letter en omstandigheden}

Bij toepassing van het kerkrecht moet van de letter uitgegaan en daaraan vastgehouden worden; echter moet deze letter niet op zichzelf, in isolement, als volstrekt afdoende voor alle voorkomende gevallen, ongeacht de omstandigheden, beschouwd worden. We hebben die letter te lezen in het licht van de Schriften en te meten aan die eis der billijkheid. Daartoe moet gebeden worden om wijsheid, Jak. 1 : 5; Col. 1 : 9, om te leren inzien hoe te werk moet worden gegaan, Ef. $1: 8$.

\section{Appèlrecht}

De Schrift kent geen recht van appèl of "hoger" beroep zoals de K.O. in art. 31 , ook niet in Ex. $18: 21$, Deut. $1: 17 ; 17: 8 .{ }^{17}$ Ook bij de door Josafat ingevoerde rechtspleging, 2 Kron. $19: 5$, is daarvan geen sprake en evenmin bij de Joden in het Nieuwe Testament, Matth. $5: 22$.

De Romeinen hadden wel appèlrecht, waarvan de apostel Paulus gebruik gemaak heeft, Hand. $25: 11,12$. Hij deed dit echter vanwege zijn apostolische roeping or, te Rome van Christus te gaan getuigen, Hand. $23: 11$. Bij het leven van de apostelen was een beroepsinstantie overbodig. Niettemin verbiedt de Schrift het instellen daarvan niet. 19

In de wereldlijke rechtspraak wordt uitoefening van het appèlrecht soms ernstig bemoeilijkt door vormvoorschriften. Geen processtuk kan worden opgemaakt, of de grootst mogelijke voorzichtig- 
heid moet worden in acht genomen, dat niet over formaliteiten zou worden gestruikeld en daardoor de procedure zou mislukken. Een procedure wordt dientengevolge een behendigheidsspel. Geen man der praktijk ziet enig bezwaar in hel opwerpen van vormmiddelen. De rechter doet aan die praktijk van ganser harte mee. In Nederland is langzamerhand de overtuiging ontstaan, dat het zo niet langer kon. De grondslag van elk procesrecht is, dat regels worden gegeven om een eerlijke rechtsstrijd te waarborgen, dat dus de eiser gehouden is en hem de gelegenheid moet worden gegeven om wat hij vordert rustig en duidelijk aan de rechter en zijn tegenpartij uiteen te zetten, en de gedaagde gehouden is en gelegenheid moet hebben om zijn verdediging behoorlijk voorbereid voor te brengen, beide om hun beweringen, zonder elkander verrassingen te bezorgen, te staven. ${ }^{20}$

\section{Beslissing moet die gronden inhouden}

Het is een onmisbaar vereiste voor een rechterlijke beslissing dat zij de gronden inhoudt waarop zij steunt. Deze motivering stelt de betrokken partij in staat haar kans van slagen in een verdere instantie te overwegen. De beweegredenen in het vonnis behoren helder en overzichtelijk, sober en bondig te zijn. Ingewikkelde volzinnen van vermoeiende lengte moeten daarom worden vermeden, gelijk de onverstaanbare termen, uitweidingen en wijdlopigheden. Vele vonnissen lijden aan nodeloze omhaal en overladenheid: het is moeilijk om kort te zijn. ${ }^{21}$

Ook de bewijslastregels volgens het strakke civiele procesrecht en niet op de grondslag van de billijkheid is tegen de leer van de Schrift.

\section{Romeinse appèlrecht}

Het appèlrecht is afkomstig uit het oud Griekse en oud Romeinse recht. In appèl mocht men zich beroepen op nieuwe feiten; men mocht ook nieuwe bewijsgronden doen gelden; het hoofddoel was, dat de rechter kwam tot een rechtvaardige uitspraak: men wilde dat er recht gedaan werd. De verklaring, dat men ging appelleren, had tot gevolg, dat de uitvoering van het uitgesproken vonnis werd opgeschort. Indien het appèl werd verworpen, dan kwamen in werking alle rechtsgevolgen van het reeds uitgesproken vonnis, gerekend vanaf de dag van de uitspraak.2

$\mathrm{Na}$ de val van het West-Romeinse Rijk blijft de kerk leven onder het Romeinse recht, gelijk een bepaling in de Lex Ribuaria luidt: Ecclesia vivit secundum legem Romanam. Het recht van appèl is in de wereldlijke rechtspraak doorgedrongen onder invloed van het Romeinse recht, en het drong ook door in de kerkelijke rechtspraak. ${ }^{23}$

Voor de Reformatie behoort appèl tot het kerkelijk recht. Zo mag een afgezette priester zich wel op een "meerdere" synode beroepen, maar niet op de keizer (Antiochië 341). Sinds het $4 \mathrm{e}$ Lateraan-concilie 1215 wordt het kerkelijk recht al strakker, ingewik- 
kelder, bedient het zich al meer van termen, ontleend aan het wereldlijk recht. ${ }^{24}$

\section{Appèl bij Calvijn}

Bij Calvijn horen we over appèl zeer weinig. Vergeten dient niet te worden dat Genève slechts een enkele kerk had. Die kerk moest zelfs macht aan de staat afstaan, wat zijzelf nooit begeerd of gewild had. Calvijn schrijft naar Zürich, dat Genève een zodanige kerkorde had als de zwakheid van deze tijden verdraagt. ${ }^{25}$

Het verband der Franse kerken is in het leven geroepen in 1559. Het krijgt al spoedig een hiërarchisch karakter. ${ }^{26}$ De nationale synode van Nimes 1572 bepaalde o.a. dat de genabuurde kerken zullen trachten ontstane geschillen, die hun kerken verontrusten, bij te leggen. De classis behandelt de bezwaren van gemeenteleden tegen hun kerkeraad, en houdt er de hand aan, dat de bepalingen der kerkenorde worden nagekomen. De classicale appèls worden doorgezonden naar de provinciale synode. Als deze appèls moeilijk te beslissen waren en omvangrijk, benoemde men een commissie van een of twee predikanten met een ouderling om de stukken te onderzoeken. Zij stelden een rapport op; kwam dit in behandeling dan verlieten de leden van de betrokken classis de vergadering omdat zij over de zaak al geoordeeld hadden. Men deed zijn best de nationale synoden, die zo weinig gehouden werden en zo overstelpt met verzoeken om te oordelen over alles en nog wat, zo veel mogelijk te ontlasten. Sommige appèls kosten de synode enorm veel tijd: de synode van Loudon bracht 15 dagen door met de kwestie van d'Arbussy, predikant en hoogleraar te Montauban. De appellanten moesten in persoon ter synode verschijnen en hun stukken meebrengen; daaronder waren er, die de omvang hadden van een boek. De synoden kunnen de stroom van appèls niet meer aan. Ze verklaren niet meer in behandeling te zullen nemen wat op vorige nationale synoden in principe reeds beslist is; al wat zuiver plaatselijk, classicaal of provinciaal is; eindelijk, al wat ter nationale synode gebracht is met voorbijgaan van de provinciale synode. De nationale synoden zouden ten slotte alleen behandelen wat betrekking had op de kerkleer, de sacramenten en wat de kerkenorde in het gemeen raakte. ${ }^{27}$

In de Artikelen van Wezel 1568 Hoofdstuk VIII Art. XI wordt appèlrecht toegestaan van kerkeraad op classis, van classis op synode. Deze artikelen hadden echter geen rechtskracht als kerkorde. ${ }^{28}$

\section{Appèlmogelijkheid sedert de synode van Emden}

De synode van Emden erkent in art. 33 appèlmogelijkheid van een door de classis afgezette predikant op de provinciale of landssynode. Ook in Particuliere Vragen (22) en Caput II (3) is sprake van beroepsrecht. ${ }^{29}$

Latere synoden maken het appèlrecht meer algemeen en de Dordtse synode geeft een herziene redactie in art. $31 \mathrm{~K} .0$. 


\section{Geen wereldlijk procesrecht}

Volgens art. 30 K.O. moeten kerkelijke vergaderingen alleen kerkelijke zaken en op kerkelijke wijze behandelen. Men moet er daarom tegen waken dat verkeerde praktijken van wereldlijk procesrecht in de kerk indringen. De rechtspraak, ook in appèlzaken, moet dus geoordeeld worden naar de Wet Gods. Deze Wet is niet een reeks van geboden, die iemand moet vervullen, maar het is de weg, waarop de Here Zijn verloste volk zet en ze voor afdwalen bewaart. Een volk zit met duistere kwesties, die heel de samenleving in gevaar brengen; de Here geeft echter in Zijn heiligdom licht. Daartoe moeten de priesters het volk ,leren", Deut. 17 : 11, dat is aanwijzing geven, de weg wijzen, directieven meegeven, naar het bevel der wet, die de wil des Heren openbaart. De rechtspraak beoogt herstel en bewaring van het leven des Verbonds, dat in de meest directe relatie staat èn tot de Here, èn tot de mede-bondgenoten.

De kerkelijke rechtspraak kan niet ademhalen in de formeeljuridische sfeer, want ze is religieus-ethisch bepaald. Richten en helpen zijn in het Hebreeuws parallelbegrippen. Richt de wees, Jesaja $1: 17$, betekent: help hem in zijn recht. „Richt mij Here”, Psalm $7: 9 ; 26: 1 ; 35: 24 ; 43: 1$, is het beroep van de verongelijkte om rechtsbijstand. In het bijzonder geldt dit voor de nood van weduwe, wees, arme en vreemdeling die in de praktijk van het leven achteruitgezet worden.

\section{De taak van de kerkelijke rechtspraak}

De taak van de kerkelijke rechtspraak is, door argumentatie uit en naar het Woord recht en onrecht aan te wijzen, gelijk en ongelijk vast te stellen. En daardoor en daarbij beide partijen te brengen op de weg des vredes, namelijk het volle, ongestoorde gedijen van het leven met de Here en de naaste in het Verbond. Een kerkelijke vergadering mag daarom ook raden en vermanen, evenals kerkleden dit onderling moeten doen: Coloss. $3: 16 ; 1$ Thess. $5: 11 ; 2$ Thess. 3 : 15 ; Hebr. 3 : $13 ; 10: 25$.

Gestreefd moet ook worden om door bemiddeling ${ }^{30}$ pacificatie te bereiken, alvorens uitspraak gedaan wordt. De bijbel geeft vele voorbeelden van arbitrale pacificatie, Job $9: 33$; $16: 21$; Gen. $31: 37$; 1 Cor. $6: 5$. Ook bij de aanvang van gereformeerd kerkverband werd arbitrage dikwijls toegepast. ${ }^{31}$

\section{Problemen van drie appèllen}

Ondanks de omstandigheid, dat het kerkelijk recht drie appèllen kent in tegenstelling tot het wereldlijk recht, waar één appèl gebruikelijk is, is het twijfelachtig of de rechtszekerheid in de kerk groter is dan in de wereld. Door meerdere appèllen worden de stukken onrustbarend vermeerderd en in de doolhof van een overstelpende hoeveelheid gegevens is de mogelijkheid van vergissing en misvatting niet geringer, maar veeleer vergroot.32 Bovendien 
wordt het contact met de meerdere vergadering daardoor eerder een papieren relatie dan een persoonlijk contact.

Is er nu verbetering te brengen in de kerkelijke rechtspraak? ${ }^{33}$

De mogelijkheid van drie appèllen heeft in onze kerken vaste voet gekregen op het voorbeeld van de Franse Kerken, die er hopeloos mee vastliepen.

Een alleszins geoorloofde weg is dat in geval van geschil beide partijen afspreken zich tot één appèl te beperken. Dit is niet in strijd met de K.O., die in art. 31 bepaalt dat een bezwaarde zich op een meerdere vergadering $\mathrm{kan}$ of mag, dus niet: moet, beroepen. ${ }^{34}$

Evenzeer is het mogelijk dat beide partijen in onderlinge overeenstemming de beslissing toevertrouwen aan scheidsrechters, 1 Cor. $6: 5$; Job $9: 33 ; 16 ; 21$; Gen. $31: 37$. Toen er een geschil was met de kerk van Franeker achtte de synode van Franeker van 1583 het billijk en recht dat elk der beide partijen twee broeders zouden aanwijzen om tot een verzoening te komen. Werden in de eerste tijd van de Reformatie aan synoden appèlzaken voorgelegd, dan trachtte men gezamenlijk eerst partijen te verzoenen; mislukte dit, dan kwam men tot een uitspraak.

Hoeveel moeite, tijd en kosten zouden de kerkelijke vergaderingen en de kerken op deze wijze kunnen besparen? En door de afsnijding van de mogelijkheid, te komen tot jarenlange processen hoeveel minder voordeel zou de boze vijand uit de hel over ons behalen! ${ }^{35}$

De rechtszekerheid behoeft bij beperking tot één appèl of tot arbitrage niet te lijden. Het is immers niet zeker dat in appèl een beter vonnis wordt verkregen. Synodeleden hebben dikwijls zich in zoveel zaken in te werken in korte tijd dat behandeling van appèlzaken schade kan lijden.

Bij alle rechtszaken moet de rechtzoekende in de kerk zich allereerst afvragen of het om zijn eigen eer en belang gaat dan wel om de eer van God. In het eerste geval moet hij overwegen of het niet beter is om schade en ongelijk te lijden. ${ }^{36}$

Dr. L. Roeleveld, senior lektor regte Universiteit van Durban-Westville.

Durban, 3 Augustus 1971.

\section{NOTEN:}

1 Prof. dr. S. du Toit: Die Kerkblad van 24 Julie 1968.

2 Ds. J. J. van der Walt: Die Kerkblad van 27 Nov. 1968.

3 Ds. J. J. van der Walt: Die Kerkblad van 14 Jan. 1970.

4 Het recht in Christus' keri naar Deuteronomium, De Reformatie, Weekblad tot ontwikkeling van het gereformeerde leven, Goes, 18 April 1953. (Waar in het vervolg slechts een datum wordt vermeld, duidt dit op publicatie in genoemd blad).

525 April 1953.

62 Mei 1953.

723 Mei 1953.

830 Mei 1953. 
96 Juni 1953.

1013 Juni 1953.

1120 Juni 1953.

1227 Juni 1953.

13 Hoe de Kerkorde niet gehanteerd moet worden, 22 Augustus 1953.

14 Eerst de Bijbel open - dan de Kerkenorde, 29 Augustus 1953.

15 Het „horen" van partijen in het licht van Schrift en historie, 5 September 1953. Rechtspraak alleen op grond van de stukken? 17 April 1954.

16 De letter van de Kerkenorde, 12 September 1953.

17 Kerkelijk appèl, 17 October 1953.

18 Appèl onder Israel, 24 October 1953.

19 Appèl door de H. Schrift niet toegelaten? 31 October 1953.

20 Mr. Th. A. Fruin: Geschiedenis van de wetenschap van het Burgerlijk Procesrecht na 1811, blz. 280 v.

21 Star Busmann: Hoofdstukken van Burgerlijke Rechtsvordering, 1948, bl. 565.

22 Iets over herkomst en geschiedenis van het Appèlrecht, 7 November 1953.

23 Recht van appèl overgenomen uit het Romeinse recht, 14 November 1953.

24 Appèl in de Oude Kerk en de Kerk der Middeleeuwen, 21 November 1953.

25 Appèl bij Calvijn, 28 November 1953.

26 Drs. D. Deddens: De eerste synode der Franse Gereformeerden te Parijs, 1559, Lucerna, Gereformeerd Interfacultair Tijdschrift, eerste jaargang, blz. 99-120.

27 Appèl in de Franse kerken, 5 December 1953.

28 Appèl in de Wezelse artikelen, 19 December 1953.

29 De Emdense Synode over appèl, 30 Jan. 1954.

30 Kerkelijke rechtspraak naar kerkelijke stijl, 27 Maart 1954.

31 Arbitrale pacificatie, 3 April 1954.

32 Scheiding van recht en feit, 1 Mei 1954.

33 Samenvatting appèlrecht, 15 Mei 1954.

34 Eén appèl, 22 Mei 1954.

35 Kerkelijke arbitrage, 17 Juli 1954.

36 Arbitrage en rechtszekerheid, 24 Juli 1954. 